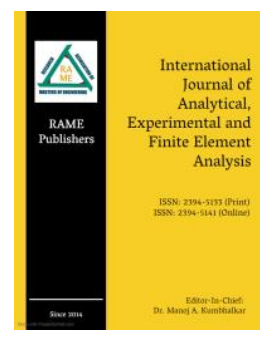

S. D. Bhalekar ${ }^{1}$ suraj.bhalekar289@gmail.com

Vaibhav Bodake ${ }^{2}$ vaibhavbodke2017@gmail.com

Abhishek Parvat ${ }^{2}$ abhishekparvat7056@gmail.com

Suchet Bhosale suchetbhosale7@gmail.com

Rushikesh Patil ${ }^{2}$ patilrushi1718@gmail.com

${ }^{1}$ Assistant Professor and ${ }^{2}$ Student Department of Mechanical Engineering, JSPM Narhe technical Campus, Narhe, Pune,

India

\title{
Design and Analysis of Wind Turbine Blade
}

Abstract - Wind turbine is utilizing the active energy come from the wind for producing the power by using the ac generators. The created electrical force is provided to the lattice. The created energy mostly relies upon the wind speed and the cleared space of the turbine. As the wind speed increments in like manner the components of the blades of wind turbine diminishes. The blades are made auto flexible with the assistance of stepper engine and control unit mounted on it. Different planning angles are discussed while keeping up with the created power. The wind turbine blades power and productivity has been estimated at various tip-speed-proportions. Present work gives a knowledge into the plan parts of a wind turbine, similar to turbine blade configuration, wind force and yield power computation. This paper presents a significant design and analysis of wind turbine blade.

Keywords - Wind turbine blade, power generation, design, analysis

\section{INTRODUCTION}

\section{A. Wind Energy}

Wind is a form of solar energy and is a result of the uneven heating of the atmosphere by the sun, the irregularities of the earth's surface, and the rotation of the earth.Wind is the movement of air from an area of high pressure to an area of low pressure. We use this wind flow, or motion energy, for many purposes: sailing, flying a kite, and even generating electricity.Wind is the cheapest form of renewable energy. The kinetic energy carried by a wind stream of certain characteristics (e.g., wind speed and air density) is the wind energy. Wind is used to produce electricity using the kinetic energy created by air in motion. This is transformed into electrical energy using wind

Research Paper - Peer Reviewed

Published online - 18 July 2021

\section{(C) 2021 RAME Publishers}

This is an open access article under the CC BY 4.0 International License https://creativecommons.org/licenses/by/4.0/

Cite this article - S. D. Bhalekar, Vaibhav Bodake, Abhishek Parvat, Suchet Bhonsale, Rushikesh Patil, "Design and Analysis of Wind Turbine Blade", International Journal of Analytical, Experimental and Finite Element Analysis, RAME Publishers, vol. 8, issue 3, pp. 82-86, 2021. https://doi.org/10.26706/ijaefea.3.8.20210703 turbine or wind energy converstion systems. Global installed wind generation capacity onshore and offshore has increased by a factor of almost 75 in the past two decades, jumping from 7.5 gigawatts $(\mathrm{GW})$ in 1997 to some 564 GW by 2018, production of wind energy is doubled between last 5 years. In 2016 wind energy accounted for $16 \%$ of the electricity generated by renewables.

\section{B. Wind Turbine}

A wind turbine is a device that converts kinetic energy from the wind Into electrical power. The energy in the wind turns two or three propeller-like blades around a rotor. The rotor is connected to the main shaft, which spins a generator to create electricity.

Types of wind turbine are,

\section{Vertical Axis Wind Turbine \\ 2. Horizontal Axis Wind Turbine}

Basic parts of wind turbine are,

- Foundation: An awesome foundation is needed to help the pinnacle and different pieces of a wind turbine which says something tones. 
- Tower: A towers that upholds the nacelle and rotor center point at its top.

- Nacelle: A lodging which contains every one of the parts which is fundamental to work the turbine productively is known as a nacelle.

- Blades: : Wind turbine blades are used to extract the kinetic energy of wind and convert to mechanical energy.

\section{Wind Turbine Blade}

The modern blade can be divided into three main areas classified by aerodynamic and structural function.

- The blade root

- The mid span

- $\quad$ The tip

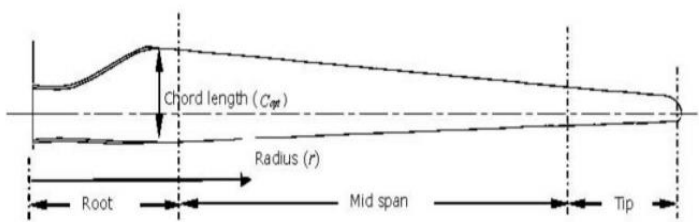

(a)

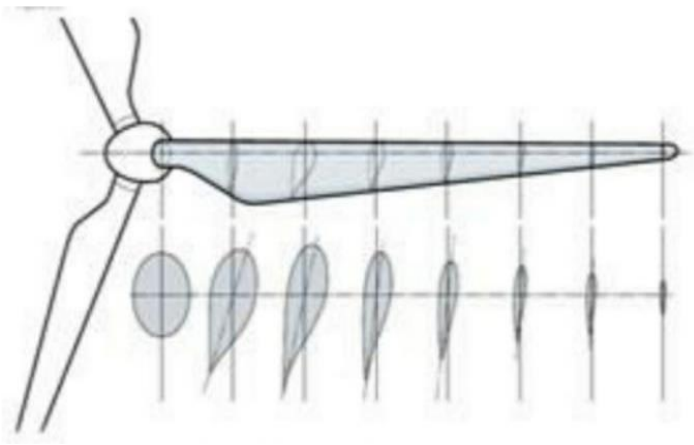

(b)

Figure 1. Internal Design of blade

\section{Objective}

- Design of the wind turbine blade in a manner that maximizes power output extracted from the wind .

- To maximize the aerodynamic efficiency of design blade.

- Analysis of the Airfoil with the help of XFOIL model.

- The blade is designed using different types of airfoils which are oriented at different angle of attack and the blade design is responsible for the efficiency for the wind turbine.

- Structural analysis of the design blade.

\section{E. Methodology}

- The design of Aerofoil in Q-Blade software.

- Analysis of the X-Foil is performe on the airfoils and the CL and alpha graphs are obtained in the Q-Blade software.

- Design of the blade in Q-Blade software.

- Further modelling is done in the CATIA.

- The mesh lab and the solid works software's are use for the conversion of the format of the files which are to be exported and imported.

\section{DESIGN AND ANALYSIS}

\section{A. Airfoils}

The underlying necessities of turbine Blade mean that aerofoils with a high thickness to chord ratio be utilized in the root district. Such aerofoils are rarely utilized in the avionic business. Thick aerofoil sections by and large have a lower lift to drag proportion. Extraordinary thought is subsequently made for increasing the lift of thick aerofoil segments for use in wind turbine plans. Public Advisory Committee for Aeronautics (NACA) four and five digit plans have been used for early present day wind turbines.

The characterization shows the mathematical profile of a NACA aerofoil where the first digit refers to most extreme chamber to chord proportion, second digit is the camber position in tenths of the harmony and the third and fourth digits are the greatest thickness to chord proportion in percent.

The NACA airfoils are airfoil shapes developed by the National Advisory Committee for Aeronautics (NACA). The shape of the airfoils is described using a series of digits following the word "NACA".

\section{B. Airfoil Import In Q-Blade Software}

The blade can be exported from the Q-blade, this is an .STL file. For further modeling in CATIA we need convert it in .IGES format. The .STL format file import in MESHLAB and convert in .DXF format then it import in SOLIDWORKS for convert .DXF to .IGES. The .IGES file is imported in CATIA and surface modeling is done. 


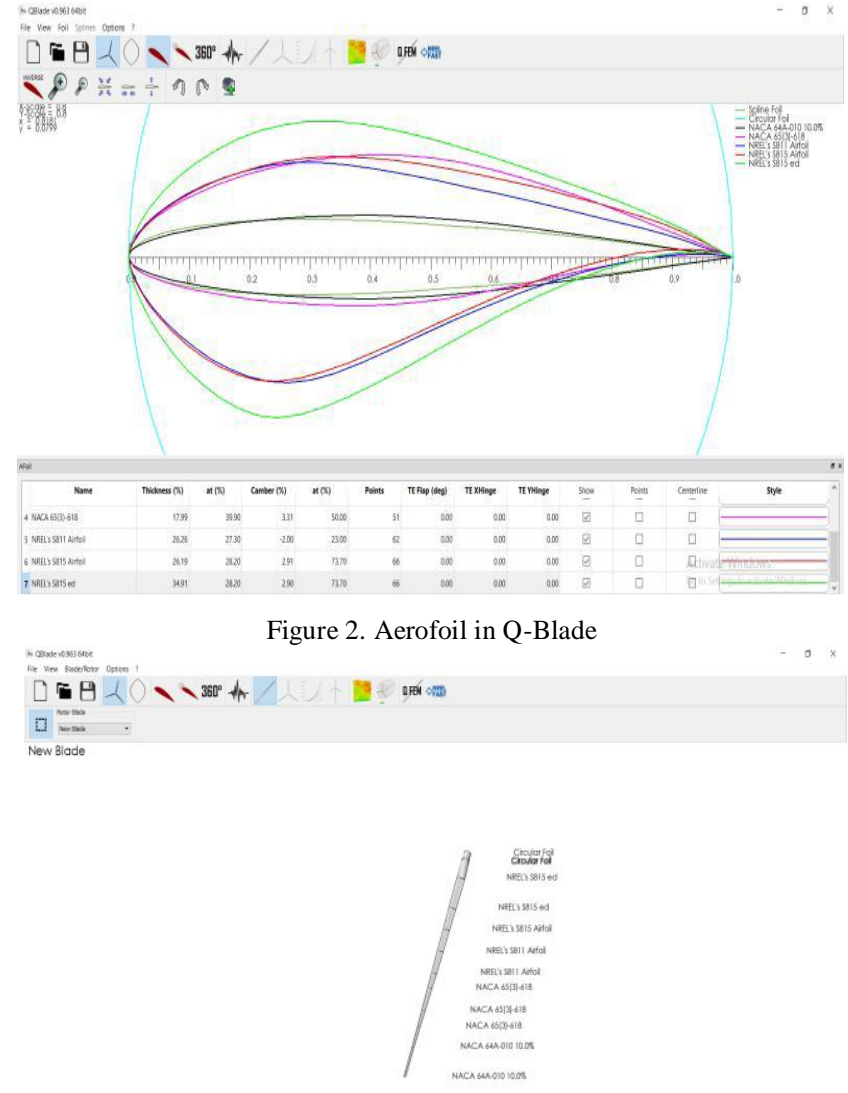

Figure 3. Blade Design

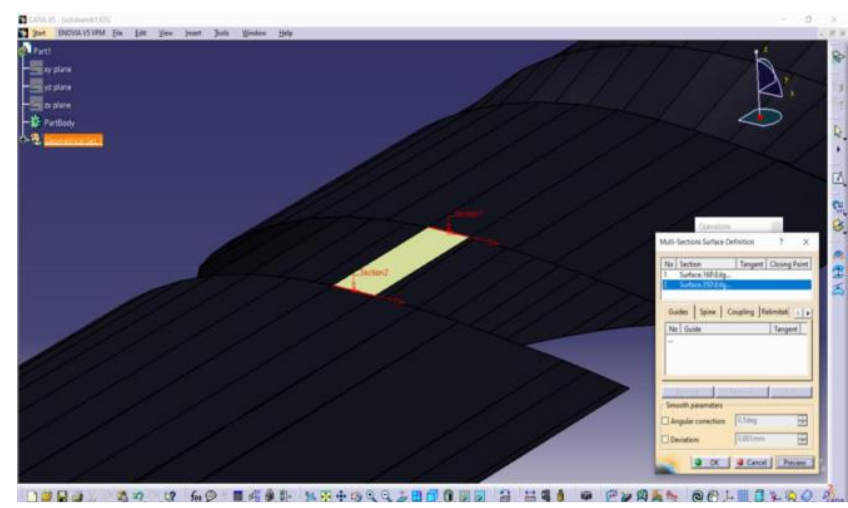

(a)

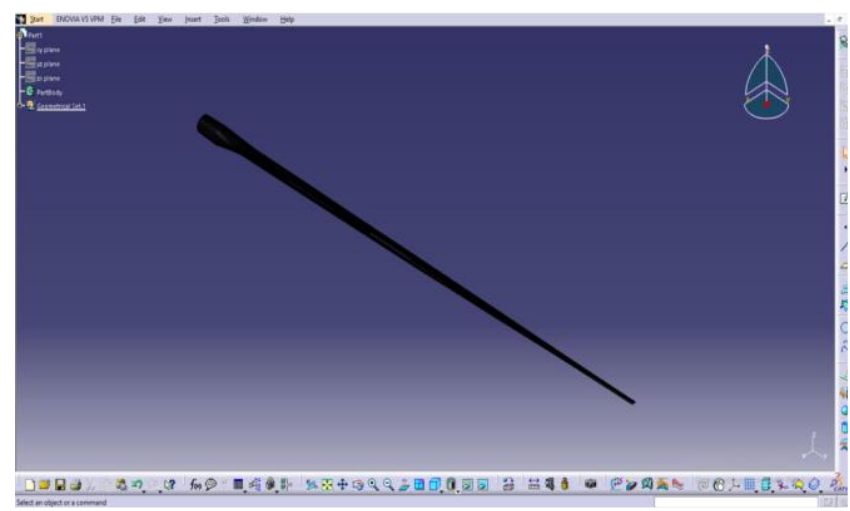

(b)

Figure 4. CATIA CAD Model
C. Analysis of wind turbine blade using ANSYS workbench

ANSYS is progressed CAD/CAM programming software that arrangements with modern ideas of Structures, Mechanics and Fluid Dynamics. The product manages Aerospace, Mechanical, Civil and Marine applications generally. This is likewise clear cut and acknowledged by numerous global organizations and assembling enterprises. Designers regularly utilize the Finite Element Method (FEM) to take care of ordinary issues of pressure, deformity, heat move, liquid stream, and so forth, utilizing business just as reason PC codes.

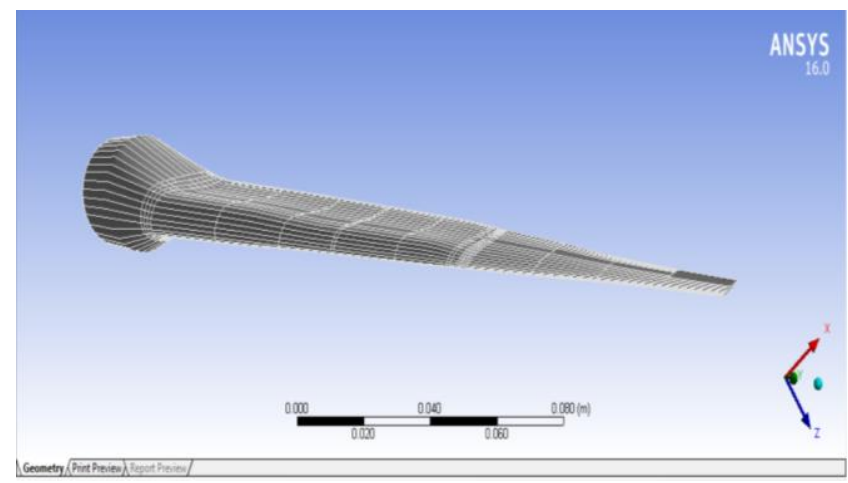

Figure 5. Analysis of Wind Turbine

TABLE I

MATERIAL PROPERTIES OF EPOXY -CARBON

\begin{tabular}{|c|l|c|}
\hline Sr. No. & Parameter & Dimension \\
\hline 1 & Young's modulus & $123.34 \mathrm{GPa}$ \\
\hline 2 & Density & $1.518 \mathrm{~g} / \mathrm{cm}^{\wedge} 3$ \\
\hline 3 & Poisson's ratio & 0.27 \\
\hline 4 & Shear modulus & $3080 \mathrm{MPa}$ \\
\hline 5 & Tensile stress & $1632 \mathrm{MPa}$ \\
\hline 6 & Shear stress & $80 \mathrm{MPa}$ \\
\hline
\end{tabular}

For the analysis purpose, the model of wind turbine blade is meshed with 130593 nodes and 13075 elements by using solid 186 hexahedral element. As an boundary condition in static structural analysis, fixed support is given at the end of the blade and Load is applied at the tip of the blade. The meshed model of blade and boundary condition applied is shown in figure 6 , figure 7 and figure 8 respectively. 


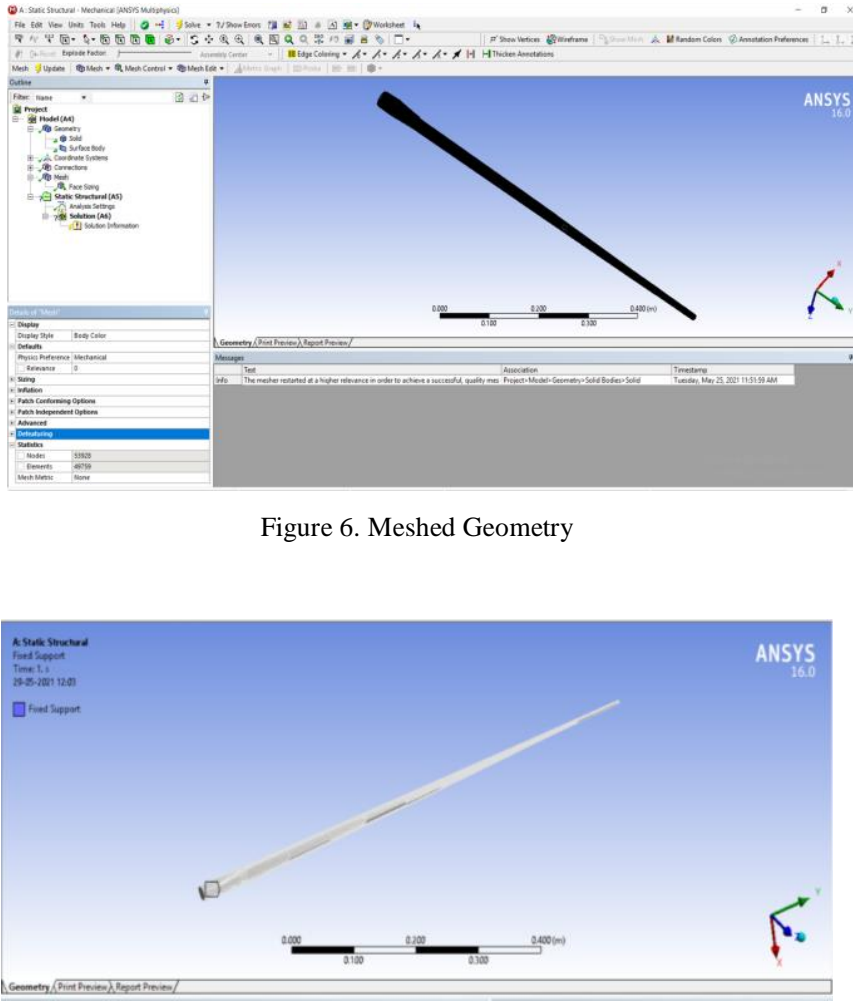

Figure 7. Fixed Support

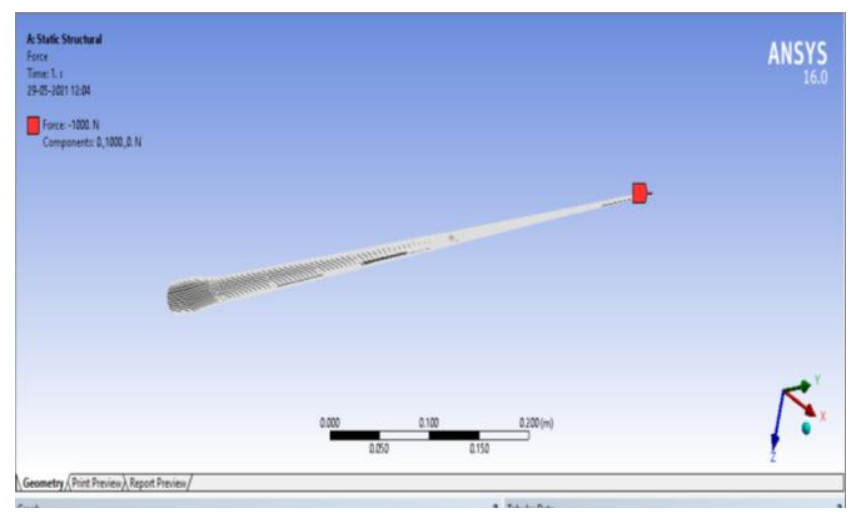

Figure 8. Applied Load

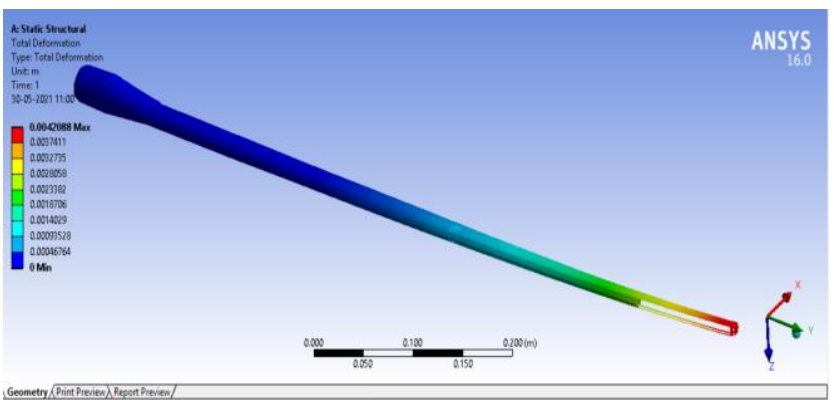

Figure 9. Deformation of blade

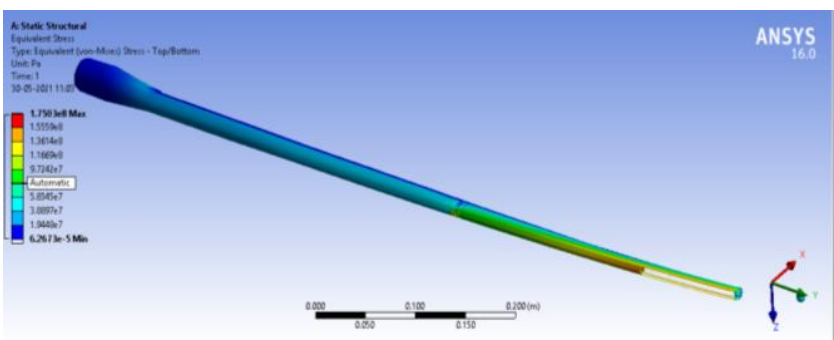

Figure 10. Equivalent Stress
TABLE II

DEFORMATION AND EQUIVALENT STRESS FOR VARYING LOAD

\begin{tabular}{|c|c|c|c|}
\hline Sr. No. & $\begin{array}{c}\text { Force Applied on } \\
\text { blade (N) }\end{array}$ & $\begin{array}{c}\text { Deformation } \\
(\mathrm{mm})\end{array}$ & $\begin{array}{c}\text { Equivalent Stress } \\
(\mathrm{MPa})\end{array}$ \\
\hline 1 & 1000 & 0.004028 & 175 \\
\hline 2 & 2000 & 0.0008417 & 350 \\
\hline 3 & 3000 & 0.01262 & 525 \\
\hline 4 & 4000 & 0.01683 & 700 \\
\hline 5 & 5000 & 0.0210 & 875 \\
\hline 6 & 6000 & 0.02525 & 1005 \\
\hline 7 & 7000 & 0.02946 & 1125 \\
\hline 8 & 8000 & 0.03367 & 1400 \\
\hline 9 & 9000 & 0.03737 & 1575 \\
\hline 10 & 10000 & 0.042800 & 1750 \\
\hline 11 & 11000 & 0.04629 & 1975 \\
\hline
\end{tabular}

Directional deformation: It is defined as Change in the shape of a body caused by the application of a force (stress). Deformation is proportional to the stress applied within the elastic limits of the material.

\section{Maximum deformation $=4.2088 \mathrm{e}-003 \mathrm{~m}$}

Equivalent stress : Equivalent stressess consider different effect resulting from multiaxial residual stress state eg. The resulting principle normal stresses, principal shear stresses, principal normal deformations or distortion energy.

Maximum equivalent stress $=175 \mathrm{Mpa}$

The yield strength of epoxy carbon is $1870 \mathrm{Mpa}$. As equivalent stress generated is $175 \mathrm{Mpa}$ at load $1000 \mathrm{~N}$, From this result we conclude that design is safe.

As the load is increase the equivalent stress is also increases and total deformation also increases simultaneously as show in the table 2 .

\section{CONCLUSIONS}

Our study explains the workings of a wind turbine and the principles that govern its operation. As a result, wind turbines have grown increasingly popular in the field of renewable energy. Aerodynamic efficiency, or power extracted from the wind, is the fundamental aim of wind turbine design.

When different loads are analyzed, it is found that the design is safe up to a maximum of $10000 \mathrm{~N}$ (10 KN). Blade will break if applied load on the blade is more than $10 \mathrm{KN}$. 


\section{REFERENCES}

[1] C. Kong, J. Bang, Y. Sugiyama, "Structural investigation of composite wind turbine blade considering various load cases and fatigue life", Energy, Volume 30, Issues 11-12, AugustSeptember 2005, Pages 2101-2114. https://doi.org/10.1016/j.energy.2004.08.016

[2] Abhishiktha Tummala, Ratna Kishore Velamati, Dipankur Kumar Sinha, V. Indraja, V. Hari Krishna, "A review on small scale wind turbines", Renewable and Sustainable Energy Reviews. Volume 56, April 2016, Pages 1351-1371. https://doi.org/10.1016/j.rser.2015.12.027

[3] Asis Sarkar, Dhirem Kumar Beher "Wind Turbine Blade Efficiency and Power Calculation with Electrical Analogy" International Journal of Scientific and Research Publications, Volume 2, Issue 2, February 2012.

[4] S.M. Habali, I.A. Saleh, "Local design, testing and manufacturing of small mixed airfoil wind turbine blades of glass fiber reinforced plastics: Part I: Design of the blade and root", Energy Conversion and Management, Volume 41, Issue 3, February 2000, Pages 249-280. https://doi.org/10.1016/S0196-8904(99)00103-X

[5] P. Fuglsang, H. A. Madsen, "Optimization method for wind turbine rotors", Journal of Wind Engineering and Industrial Aerodynamics, Volume 80, Issues 1-2, 1 March 1999, Pages 191-206. https://doi.org/10.1016/S0167-6105(98)00191-3
[6] P.G. Migliore , M.C. Cheney "Feasibility Study of Pultruded Blades for Wind Turbine Rotors" 2000 ASME Wind Energy Symposium, 2000, https://doi.org/10.2514/6.2000-61

[7] Arturo Del Valle-Carrasco, Delia J. Valles-Rosales, Luis C. Mendez, Alejandro Alvarado-Iniesta, “A site-specific design of a fixed-pitch fixed-speed wind turbine blade with multiple airfoils as design variable" International Journal of Energy And Environment, Volume 6, Issue 3, 2015, pp.287-298.

[8] P. Fuglsang, H.A. Madsen, "Optimization method for wind turbine rotors" Journal of Wind Engineering and Industrial Aerodynamics, Volume 80, 1999, pp 191-206. https://doi.org/10.1016/S0167-6105(98)00191-3

[9] Meng-Kao Yeh1 and Chen-Hsu Wang, "Stress analysis of composite wind turbine blade by finite element method", IOP Conference Series: Materials Science and Engineering, Volume 241, Volume: 05 Issue: 06, June-2018. https://doi.org/10.1088/1757-899X/241/1/012015

[10] M Damiano and A D'Ettore, “Structural design of a multimegawatt wind turbine blade with One Shot Blade ${ }^{\circledR}$ Technology", Journal of Physics: Conference Series, Volume 1037, Issue 4, 2018 https://doi.org/10.1088/1742-6596/1037/4/042002 